(REVIEW ARTICLE)

\title{
Cleaner fish behavioral ecology: Its implications toward wild fishery and salmonid aquaculture sustainability
}

\author{
Jumah Yashier Upling 1,2,* \\ ${ }^{1}$ Aquaculture Department, College of Fisheries, Mindanao State University - Tawi-Tawi College of Technology and \\ Oceanography, Sanga-Sanga, Bongao 7500, Tawi-Tawi, Philippines. \\ 2 Institute of Aquaculture, College of Fisheries and Ocean Sciences, University of the Philippines Visayas, Miagao 5023, \\ Iloilo, Philippines.
}

Publication history: Received on 11 May 2020; revised on 15 May 2020; accepted on 18 May 2020

Article DOI: https://doi.org/10.30574/gscarr.2020.3.2.0034

\begin{abstract}
Cleaner fish is a keystone species in their natural ecosystem for they have specialized feeding habits that are removing and eating ectoparasites which are colonizing the skin, mouth, and gill cavities of larger fish. Their presence dictates the species distribution, diversity, recruitment, and abundance of different teleost species. They play a very important role in the survival, growth, and welfare of other fishes. They established cleaning stations where a certain location turns into a very rich fishing ground visited by various species of demersal, pelagic including migratory and cartilaginous fishes, that made a stopover and an influx of visiting species that search for it. They formed an interaction known as "cleaning symbiosis" in which cleaners gain nutrition and protection from predators and in return for a cleaning service. Aquaculture, on the other hand, is one of the destructive anthropogenic activities if not well managed. One of the highlighted effluents from aquaculture is the use of pharmaceutical chemical treatments to ease diseases of cultured stocks. Hence, a sustainable and eco-friendly approach to mitigate and eradicate diseases is one of the main concerns of the aquaculturist nowadays. Salmon aquaculture encountered fish louse as one of the most destructive parasites in the industry. However, these parasites have been controlled by a cleaner fish to the extent of suppressing them. These cleaning potentials provide a long-term control of sea louse infestation over a production cycle, provided that cleaner fish are maintain healthy and confined. Thus, the ecological and aquaculture impact of the cleaner fish is being highlighted in this review.
\end{abstract}

Keywords: Cleaning symbiosis; Wrasse; Ectoparasite; Chalimus; Lumpfish.

\section{Introduction}

The ectoparasites salmon louse (Lepeophtheirus salmonis) and sea lice (Caligus elongatus) are a serious problem in salmon aquaculture (Salmo salar) and rainbow trout (Oncorhynchus mykiss). These parasitic copepods attach to fish and feed on their mucus and tissue, reducing feed conversion efficiency and causing sores, thereby increasing farming costs and reducing the value of the product. The rate of infestation started from chalimus, pre-adult males and females together with adult males which is believed to be external in origin rather than within a farm [1]. Many pharmaceuticals have been used to control sea lice, typically administered using bath treatments or by addition to feeding. However, overuse of pharmaceuticals has resulted in the development of resistant strain of salmon lice [2]. This phenomenon led to development for an alternative and sustainable delousing treatment such as the use of cleaner fish. Cleaner fish such as; ballan wrasse (Labrus bergylta), corkwing wrasse (Symphodus melops), rock cook (Centrolabrus exoletus), goldsinny

\footnotetext{
* Corresponding author: Jumah Yashier Upling; Phone: +639778166822 email: ajofflink@gmail.com
} 
Jumah YU. / GSC Advanced Research and Reviews, 2020, 03(02), 020-030

wrasse (Ctenolabrus rupestris), cuckoo wrasse (Labrus mixtus), and lumpfish (Cyclopterus lumpus) have been successfully controlled sea-lice infestation on farmed Atlantic salmon (S. salar) and rainbow trout (O. mykiss) [3]. Cleaner fish living together with the salmonids in the net pens has been most successful. The use of cleaner fish in Norwegian aquaculture started in the 1980s when researchers at the Institute of Marine Research in Norway tested the use of wrasses to reduce infestations with salmon lice on farmed Atlantic salmon. Results from the first laboratory-scale production, and gradually adopted by commercial-scale operations. In the year immediately following these trials, salmon lice were kept under control by the use of newly introduced anti-parasitic drugs, and interest in the use of wrasses was only moderate. However, during the last decade, the demand for cleaner fish has increased due to the increasing lack of efficacy of drug treatment. This is reflected in the recent steep increase in the number of cleaner fish used in Norwegian aquaculture [3]. Tropical cleaner wrasse species have not yet been considered for aquaculture. Although several studies have been conducted on tropical cleaner fish [4] but there is no intensive use of tropical species on a commercial scale. Thus, this paper focuses only on a commonly used cleaner fish in a global salmon industry, particularly in the temperate region.

In the natural environment, cleaner fish have specialized feeding habits that are removing and eating ectoparasites that are colonizing the skin, mouth, and gill cavities of larger fish. This interaction is known as "cleaning symbiosis" in which cleaners gain nutrition and protection from predators and in return for a cleaning service. Cleaner fish have been well described from tropical coral reefs, where there may be "cleaning stations" where fish position themselves and signal that they are ready to clean "client fish". Although fish behavior has not been well described in temperate water, there is anecdotal information indicating that migrating wild Atlantic salmon (S. salar) and rainbow trout (S. trutta) stop in shallow water areas that may represent cleaning stations [3]. A specific cleaning location facilitated increased cleaning frequency. On-site study on blue-headed wrasse revealed that cleaning frequency increased with the number of juvenile cleaners and clients at the cleaning stations [5]. Because of the cleaning stations, some fish travel long distances just to be cleaned, and thus the effect of cleaner may extend much further than the vicinity habitat. The influx of visiting clients which are attracted by cleaner fish may increase species diversity and abundance of a certain fishing ground [6]. Therefore, this paper also highlighted the key role of cleaner fish in a sustainable wild fishery.

\section{Species of cleaner fish used in delousing activity of the salmonid farm}

The used of cleaner fish in salmon farm began in 1988 with goldsinny wrasse (C. rupestris), followed by corkwing wrasse (S. melops), later for rock cook (C. exoletus), then juvenile ballan wrasse (L. bergylta) and finally the lumpfish (C. lumpus) [2]. Among the species, corkwing was by far the most important wrasse species, constituting almost $52 \%$ in biomass and $56 \%$ by a number of landings reported by species after 2010 in Hardangerfjord. This is followed by ballan wrasse made up 34\% in biomass but only $14 \%$ by number due to its larger size [7]. However, recent report on overall cleaner fish used, lumpfish were the most predominant (56\%) followed by goldsinny and corkwing wrasse (18\% and $17 \%$, respectively), then ballan wrasse (5\%) and other wrasse (4\%) (Barrett et al., 2020) [8].

\subsection{Goldsinny wrasse (Ctenolabrus rupestris)}

Goldsinny wrasse is the smallest species of wrasse used in Norwegian aquaculture, with a maximum length of approximately $20 \mathrm{~cm}$ and usually up to $14 \mathrm{~cm}$. It may live to 20 years of age. It has the widest distribution and is found along most European coastlines, north to Trom county, although its occurrence is sparse in the northernmost part. It inhabits low-energy, shallow-water habitats with vegetation and shelter, and is the most commonly captured wrasse in many areas around half of the total catch of wrasses are this species. It is the main species imported from Sweden [3].

\subsection{Corkwing wrasse (Symphodus melops)}

The corkwing is found north to Mid-Norway (Trondelag). It is particularly numerous along the west coast. It prefers shallow-water habitats, with dense vegetation where the male establish territories and build nests during the mating season. Some males are morphologically identical to females and act as "sneakers" during mating season. This species may live for 10 years, but does not usually survive for so long. On the south coast, they commonly live to three years of age. This species is not considered very robust, and high mortalities have been recorded during and after transport and after transfer to the net pens. It appears vulnerable to bacterial infections, and high losses have been linked to catch and use during spawning season [3]. 
Jumah YU. / GSC Advanced Research and Reviews, 2020, 03(02), 020-030

\subsection{Rock cook (Centrolabrus exoletus)}

Rock cook is typically found in the same habitats as the corkwing wrasse but has a more southern distribution. It is usually less numerous. The rock cook is protected in Sweden, and thus not imported to Norwegian fish farming areas. This species is considered a less efficient cleaner fish than ballan and goldsinny wrasses, and many farmers do not use it [3].

\subsection{Ballan wrasse (Labrus bergylta)}

Ballan wrasse is the largest species of wrasse used in Norwegian aquaculture, growing to over $60 \mathrm{~cm}$ in length. It is found north of Trøndelag. It is abundant in the seabed vegetation, particularly in the lower seaweed zone and kelp forest. It is well adapted to exposed, high energy habitats. It is a long-lived species that may survive up to 25 years. They are hermaphroditic, and all individuals are born female. It is relatively robust and may be used as a cleaner fish together with large salmon. This species may be grown together with the salmonids throughout the production cycle, that is why farmers preferred the juvenile stage [3].

\subsection{Lumpfish (Cyclopterus lumpus)}

Lumpfish is found along the North Atlantic coastline. It lives most of the time pelagically, feeding on plankton and pelagic invertebrates. This ability and willingness for attachment to any firm surfaces must be considered when keeping lumpfish in captivity, e.g., in terms of equipment design for stocking and transport. The increased popularity of lumpfish compared with wrasse seems, essentially, to derive from a perception that lumpfish are more robust to transport/handling, etc., retain their lice-eating activity at lower water temperatures, and have a considerably shorter production time [3].

\section{Ecological role of cleaner fish in a sustainable fishery}

It has long been recognized that in nature, a certain species of marine animals have come to specialize in cleaning parasites and necrotic tissue from fishes that visit them. This mutually beneficial behavior promotes the well-being of the host fishes and provides food for those that do the cleaning. It appears that cleaning symbiosis may help to explain the range of species and the make-up of populations found in particular habitats, the patterns of local movement and migration, and the natural control of disease in many fishes [9]. It was also highlighted by Grutter et al., [6] that cleaner fish affect the local distribution of many coral reef fishes at Lizard Island, Australia. And has broad implications for understanding fish community structure and coral reef management. In addition to predation, competition, and ecological and stochastic processes, cleaner fish also appear to affect the local distribution of fish. Many of the visiting fish species are of commercial value. Some fish travel long distances to be cleaned, and thus the effects of cleaners may extend much further than the vicinity of reefs. Limbaugh [9] also noted during the summer of 1955 in the Gulf of California near Guaymas, cleaning behavior appeared to be concentrated at rocky points and each point was manned by two butterflyfish and one angelfish. This was assumed that the concentration of other fishes arose from the fact that these points constitute the intersection of the communities of fishes on each side. This notion was also confirmed from Randall [10], that cleaning wrasses in the Society Islands, observed that fishes came from comparatively long distances to the sites occupied by the cleaners, not just from the immediate community. The same observation was also reported by Pederson brother in the Bahamas that cleaner fish congregate in regular "cleaning stations" in the coral reefs and attract host fishes from large areas. The presence of cleaner fish in localities accounts for a great part for the large assemblage of other fishes that are so frequently seen there. Even a small cleaning station in the tropics may process a large number of fish in the course of a day. Limbaugh [9] even saw up to 300 fish cleaned at one station in the Bahamas during one six-hour daylight period. Some of the fishes pass from station to station and return many times during the day; those that could be identified by visible marks, such as infection spots, returned day after day at regular time intervals. Altogether it seemed that many of the fishes spent as much time at cleaning stations as they did in feeding. At cleaning stations inhabited by thousands of cleaning organisms, cleaning symbiosis must assume great numerical significance in determining the distribution and concentration of marine populations. It was also documented by Limbaugh [9] that certain fishes in the wild such as the opaleye (Girella nigricans), the topsmelt (Atherinops affinis) and the blacksmith (Chromis punctipinnis), a crowd so densely about a golden-brown wrasse (Oxyjulis californica) that it is impossible to see the cleaning activity. And oftentimes a single cleaner was swarming around with several hundred fish that the researchers thought they were spawning aggregation. Judging by the diversity of its clientele, the golden-brown wrasse is well known as a cleaner to many members of the marine community. Among the species that seek out its 
services, Limbaugh [9] counted pelagic fishes as well as the numerous species that populate the kelp nearer shore. The black sea bass (Stereolepsis gigas) and the even larger ocean sunfish (Mola mola) seem to visit purposely to the outer edge of the kelp beds, where they attract a large number of cleaner wrasse, which flock around them to pick off their parasites. It was also observed that golden-brown wrasse at work on the bat ray (Holorhinus californicus), showing that the symbiosis embraces the cartilaginous as well as the bony fishes. This led to the assumption that the removal of heavy exploitation of single well-known cleaner fish might affect the overall species biodiversity, and abundance of a certain habitat. In the work of Bshary [11], cleaner wrasse (Labroides dimidiatus) was pronounced as a key organism for reef diversity at Ras Mohammad National Park, Egypt after knowing the effect of removing this species from some reef patches and adding to others. Although no immediate effects were observed on fish abundance however, a 4-20 months significant decline in fish diversity was detected. It was also observed that the presence or absence of cleaner fish also affected the distribution of resident fish that hardly ever interact with them. But the effects were more pronounced for client species that visit reef patches which soon move off again after no interaction with cleaner fish. The same result was observed in a modest field experiment in the Bahamas when all known cleaning organisms were removed from two small, isolated reefs where fish seemed particularly abundant. It was observed that within a few days the number of fish was drastically reduced; within two weeks almost all except the territorial fishes had disappeared. This experiment also demonstrated the importance of cleaning symbiosis in maintaining the health of the marine population. Many of the fish remaining developed fuzzy white blotches, swelling, ulcerated sores, and frayed fins. These abnormalities certainly occurred because of the absence of cleaner fish [9]. Aside from the short term effect on the removal of known cleaner fish in a certain location, Waldie and colleagues [12] conducted a long-term effect on the removal of well known cleaner fish L. dimidiatus on coral reef communities in Lizard Island, Australia. In this study, all cleaner wrasse were removed from a patch reef and maintained cleaner-fish free for over 8.5 years. And this activity resulted in a reduction of resident fishes and fewer species compared to the reef with cleaner fish. It was observed that the growth rate and/or survivor of resident fish were also affected. And fish recruitment was also affected in which juveniles of visitors fish were $65 \%$ less abundant on reefs without cleaners. This demonstrates further that the removal of single species of known cleaner fish affects growth, species richness, biodiversity, and abundance leading to a community-wide effect on the fish population. Therefore, Limbaugh [9] concluded that most concentrations of reef fishes may similarly be understood to be cleaning stations. And cleaning symbiosis would, therefore, account for the existence of such well-known California sport-fishing grounds as the rocky points of Santa Catalina Island, the area around the sunken ship Valiant off the shore of Catalina, the La Jolla kelp beds and submarine canyon and the Coronado Islands. These show evidence that cleaner fish determine the rich and sustainable fishing grounds. Thus, some authors suggested that the introduction of cleaner fish may be useful for increasing fish diversity on artificial or damaged reefs. However, guidelines on the stocking of introduced species should be considered. And the removal of cleaners from reefs on a commercial scale should be exercised in caution according to Grutter and colleagues [6].

\section{The use of local wrasse as a sustainable cleaner fish in salmon farm}

Part of sustainable aquaculture practices is the use of native cleaner fish species available in the area. Because of the debated issue on the genetic impact of farmed fish escaping aquaculture such as cleaner fish imported from other regions. There was a report by Faust et al., [13] that translocated corkwing wrasse escaped from the salmon farm and was able to hybridize with local populations. This wrasse which was transported long distances resulted in an increasing number in Flatanger, Norway, an area heavily relying on the import of cleaner fish from Skagerrak. This was proven by using a genetic marker that the Flatanger population of wrasse is a result of considerable gene flow from the southern population in Skagerrak and Kattegat.

Norwegian wrasse species that are commonly used as cleaner fish are highly autochthonous and stationary, and do not migrate long distances from their natural in-shore residence. It is therefore conceivable that initially conspecific wrasse populations may, as a result of long-term geographical separation, have evolved into distinct subspecies that are particularly adapted to their local environment [13]. It is likely that local populations of wrasse are genetically isolated and transport operations to other places will, therefore, affect stock structure genetically. It was mentioned by Skiftesvik et al., [7] that genetic analyses of the various wrasse species and population are scarce, especially for the time period before the wrasse fishery began. The work of Sundt and Jorstad [14] \& [15] as cited by Skiftesvik et al., [6] [7] who reported significant genetic differences between locations using allozyme analysis, including samples collected between the inner fjord and coastal. Another significant difference in a goldsinny was also found in samples caught in southern Norway (Arendal), transferred to mid-Norway, and compared with local wrasse [7]. Another possibility pointed out by Skiftesvik and colleagues [7] was the transfer of wrasse pathogens during the import of wrasse between regions. 
Jumah YU. / GSC Advanced Research and Reviews, 2020, 03(02), 020-030

The origin and life histories of the cleaner fish are important factors that affect the risk. The disease status of wildcaught cleaner fish is, generally, poorly known. Translocations of such fish may result in the introduction of new pathogens to farmed salmonids. Stocking and screening of wild-caught cleaner fish prior to their introduction to the salmonid net pens could mitigate the risk. The risk of introducing cleaner fish-specific pathogens is considered higher than the risk of introducing salmonid pathogens [3].

\section{Cleaner fish as a sustainable biological delousing agent in aquaculture}

Cleaning behavior of Labridae in captivity was first seen when British Labridae (Crenilabus melops) in the public aquarium taking parasites from the bodies of pink bream (Pagellus centrodontus). This cleaning activity mostly occurs after the lights are first turned on when the hosts remain stationary to be cleaned [16]. This observation has led to the investigation of using cleaner fish as an alternative way of removing sea lice in salmon aquaculture. The use of cleaner fishes reduces or avoids the need to use parasiticides to control sea lice, thereby improving fish health, saving costs, and the farmed fish can be harvested without drug residue [4]. Cleaning activities of wrasse in captivity was also proven by succeeding studies. Such as when ballan wrasse from the cultured and wild compared for their efficiency as delousing agents of salmon showed comparable results. During the experiment, louse prevalence decreased from 9 lice on average per fish to less than 1 in the sea cages stocked with wrasse. It was approximated that wrasse was able to consume 4000 lice in just seven days, which represents a minimum consumption rate of 23 lice per wrasse per day. Although in this study showed that wrasse groups that are wild and cultured efficiently removed pre-adult and adult lice from the salmon, but not chalimus stage lice. When in fact, the number of sea lice chalimus stages on the salmon increased throughout the experiment. This is because they could not see them on the side of the salmon, either because they were too small and/or because of low target contrast. The target contrast between the salmon (silver) and the louse (brown), rather than the shape of the target (e.g. egg strings protruding off of the female louse), is probably what attracts the wrasse. However, the wrasse effectively reduces the older lice stages and therefore, it would only be a matter of time until these chalimus will be removed. Overall implication demonstrates that ballan wrasse from cultured can be introduced into the salmon cages and can keep salmon lice load at very low levels [2]. It was also reported that cleaner fish such as corkwing (S. melops) and goldsinny (C. rupestris) have been successfully controlled sea lice infestation on farmed Atlantic salmon smolts (S. salar). Lice levels were generally maintained below five mobile stages per fish using ratios as low as one to 250 salmon, and cleaner-fish were shown to be a more effective lice control method than conventional chemical treatments in the case of diseased or stressed salmon. Cleaning behavior was observed throughout the day though a peak in cleaning activity was recorded in the early morning for corkwing and at midday in the case of goldsinny. Individual wrasse consumed up to 58 lice as seen in their gut content [17]. Corkwing wrasse was also found to clean salmon in a sea cage experiment. The experiment on wrasse cleaning capacity in sea cages conducted in 1987 gave the first promising indications. This happened on October 26, 1987 when the number of adult lice on 40 post-smolts ( $300 \mathrm{~g}$ ) was recorded before the cleaner wrasse was released into a small cage. And the total number of lice was reduced by $57 \%$, from 1329 to 565 lice, after 24 hours. This suggested that the average cleaning efficacy was 28.3 lice per wrasse per day. While goldsinny has also been reported cleaning salmon in a sea cage, that consumes up to 20 lice found in the stomach. And this species was reported to clean 45 lice in just 1.5 hours in an individual aquarium experiment. Lice control in cages using rock cook was also done by Bjordal [18] and by the end of their experiment, it was indicated that a single rock cook could clean 22 salmon.

A detailed delousing activity of wrasse in salmon was documented by Bjordal [18] using underwater cameras installed in tanks, aquaria, and sea cages. It was observed that there was no aggressive behavior of salmon towards cleaner wrasse. And there was no solicit cleaning behavior performed by salmon which is commonly exhibited by clientele in the wild environment. When salmon was put into an aquarium or tank with cleaner wrasse, initially the wrasse kept a distance until the salmon came to a resting position after swimming vigorously for a few minutes. Then after 5-15 minutes, one or a few wrasses approached the salmon and started to inspect and then clean it. Normally when first encountered, wrasse initiated cleaning the tail region, then the central parts, and eventually proceeded to head portion to clean lice. A wrasse would normally inspect by swimming slowly alongside a salmon before nibbling one or several lice. Using different species of wrasse, goldsinny normally initiated the cleaning, and even when offered a lice-infested salmon for the first time, the goldsinny started cleaning as soon as 5 minutes after salmon came into a resting posture. However, among the three species tested, rock cook was considered as the most aggressive which initiated cleaning activity in a relatively short time in aquaria and tanks. But cleaning behavior in cages was observed mainly with goldsinny. The wrasse normally stayed along the side walls or deeper than the salmon. As salmon were cruising slowly 
in the central part of the cage, goldsinny would typically enter the salmon school, swim alongside a salmon for a half to one round, inspect it, and nibble several lice before returning to the cage wall.

The on-going challenge for the salmon industry is to find an efficient sea-lice control. Cleaner fish such as wrasse became an alternative to medicine in eradicating sea lice due to its sustainability in some aspects. However, the use of wrasse has become controversial especially when winter is coming. Cleaner wrasse tends to become inactive at low temperatures. This failure performance of wrasse in cleaning activity during winter led to its replacement with the new one, and this is the lumpfish (C. lumpus). Lumpfish continue to feed on sea lice even at low temperature which is considered promising species in the salmonid aquaculture [19]. In a passive-acoustic telemetry study done in commercial Scottish salmon, sea-pen proved that the cleaning behavior of ballan wrasse is entirely temperaturedependent. The effect of temperature causes their vertical distribution which is repeatedly observed resting at the pen bottom [20]. Their low metabolic rates and inactivity at $5-10^{\circ} \mathrm{C}$ suggests that their efficiency as cleaner fish will be limited in winter and in higher latitude locations [21]. While elevated temperature promotes growth and feed efficiency as observed in farmed ballan wrasse juveniles [22]. The clear evidence of lumpfish grazing efficacy on sea lice was also reported by Imsland et al., [23], through gastric lavage which was performed every 2 weeks for 54 days farmed in low temperature $\left(9-12^{\circ} \mathrm{C}\right)$. The efficiency was manifested by lower average numbers of pre-adult, mature males and females stages of $L$. salmonis per salmon. Lumpfish even further reduced the mature female stage of $L$. salmonis to levels equal to or lower than the counts recorded prior to the start of the experiment. This indicates that this species is a suitable cold-water option for the biological delousing of Atlantic salmon. A significantly lower sea lice infection levels were also seen on Atlantic salmon when reared together with small lumpfish, as compared to the salmon without lumpfish. However, this trend became not obvious when salmon reared with larger lumpfish [24]. Aside from the temperature, there are several factors that affect the efficacy of the cleaning activity of cleaner fish. And among these are the presence of biofoulants in net cages, zooplankton in the water, salmon feed, etc. However, other findings revealed that the presence of organisms associated with biofouling had a moderate, but positive influence on the prevalence of sea lice in the lumpfish diet. Furthermore, findings indicate that biofoulant, and the subsequent availability of alternative prey organisms, does not reduce the cleaning efficacy of lumpfish [25]. In spite of that, other study reported that lumpfish showed a steadily decreased of metabolic rates measurement in hypoxia trial which strongly suggest that it requires normoxic condition to efficiently function as a cleaner fish [26].

Part of cleaning symbiosis is cheating which often resulted in a temporary disturbance in the symbiotic relationship. Cheating happens when a partner provides less commodity for their benefit received, in such cases oftentimes resulted in biting. Because parasites may vary seasonally, cleaner fish tempt to cheat by removing and ingesting client fish mucus and scales in addition to their ectoparasites. This cheating behavior might also exist in pens and cages of salmonid farms, and their effect may have an impact on the growth of salmon. However, recent evidence suggests that facultative cleaner fishes such as wrasses including lumpfish cheat less than dedicated cleaner fish [4]. And several studies proved that the use of commercial cleaner fish has no effect on the growth and condition factor of farm salmon. And one of those is the work of Imsland et al., [23] in which findings showed that the presence of lumpfish did not have any negative short and long-term effects on feed conversion ratio (FCR) or specific growth rate (SGR) in salmon.

\section{Cleaner fish aquaculture as a sustainable commercial source}

Because of the great demand for cleaner fish in the salmonid global industry, production needs to increase and this could only be sustained through aquaculture. In the case of lumpfish which is now commonly used, that need to increase production in order to meet global industry satisfaction. Production methods of this species in captivity were recently reviewed by Powell et al., [19]. Fertilization in captivity of this is being done using a 'dry method' that is mixing the sperm with eggs and adding seawater to activate the sperm. On the other hand, wild-caught males sperm may need to be dissected in order to obtain the testes, which are then macerated and passed through a sieve to get the sperm. It is also possible to obtain viable sperm from the testes several days after removal from the fish and sperm can also be cryopreserved. Spawning of wild females in small tanks can be done even without the procurement of substrate. Lumpfish eggs have been successfully reared in UV-treated upwelling incubators consisting of $70 \mathrm{~L}$ hoppers loaded with 0.5-1.0 kg of eggs, equivalent to $50000-100000$ eggs per hopper. In larviculture, the critical period for survival in lumpfish can be at around $25-30$ days post-hatch $(\mathrm{dph})$ at $10^{\circ} \mathrm{C}$, which is consistent with weaning stress, average survival at $30 \mathrm{dph}$ being recorded is at $78 \%$. Rearing of lumpfish larvae under controlled conditions was the first attempt and probably took place in the mid-1980s. However, large-scale larviculture trials began in the early 1990s, by which time larvae derived from artificially spawned broodstock were weaned on day-old Artemia nauplii four to 6 days after 
hatching. At the Center for Sustainable Aquatic Research (CSAR; Swansea, UK), recently hatched lumpfish larvae are initially fed enriched Artemia nauplii and after two to 3 weeks are weaned on $250 \mu \mathrm{m}$. Feed size is then gradually increased to $360-650,580-840 \mu \mathrm{m}$ and finally $800-1200 \mu \mathrm{m}$ over a further $2-3$ weeks. One month later, pellet size is increased to $1.5 \mathrm{~mm}$, and eventually, when lumpfish reach $10 \mathrm{~g}$ a pellet size of $1.8 \mathrm{~mm}$ is used. In experimental conditions where food density was maintained constant at 100 Artemia $\mathrm{L}^{-1}$, lumpfish larvae grew faster when food was administered continuously. Making Artemia and other live feed biosecure might also be desirable to avoid these posing an infection risk to lumpfish. In on-growing lumpfish, the highest growth rates have been observed for automatic feeders compared to hand-fed fish, for fish reared at a low stocking density compared to high density and fish fed under a more intensive feeding regime. Overall, it was thought economically viable to rear lumpfish in cages until sexual maturation. Recent studies indicate that the optimal temperature for the growth of cultured lumpfish decreases with body size. Thus, whilst a temperature of $15.7^{\circ} \mathrm{C}$ appears optimal for the growth of juveniles $11-20 \mathrm{~g}$ in mass, it decreases to $8.9^{\circ} \mathrm{C}$ for $120-200 \mathrm{~g}$ fish [27]. The growth rate of lumpfish in captivity appears to be rapid; juveniles may attain an specific growth rate (SGR) of 1.5-3.5\% per day, or increase their mass to $20-260 \mathrm{~g}$ in about 3 months at $13^{\circ} \mathrm{C}$ with constant light [28]. It is thus possible to produce lumpfish ready for deployment at a size of c. $60 \mathrm{~mm} \mathrm{(10} \mathrm{g)} \mathrm{in} \mathrm{as} \mathrm{little}$ as 4 months, although there is much variation among families, and some may take up to 7 months [29]. In captivity, lumpfish can become sexually mature in their second year, when they reach $1.5-2.0 \mathrm{~kg}$ (14 months post-hatch in Canada) which should make it possible to develop elite lines although marker-assisted selection in a few generations.

The increasing demand for cleaner fish in Norwegian aquaculture in recent years, combined with the ethical, practical, ecological, and biosecurity-related concerns associated with the use of wild-caught wrasse, has given rise to a whole new industry devoted to the production of farmed cleaner fish. A shift towards the use of farmed, instead of wild-caught, cleaner fish will facilitate improved infection control (e.g., through vaccination and screening), targeted breeding (e.g., towards domestication and increased lice-eating activity), and less season-dependent delivery. It may also contribute to relieving the exploitation pressure imposed upon wild wrasses populations. Due to the increase in farms producing lumpfish, the majority of cleaner fish used in Norwegian aquaculture have been of farmed origin since 2015. Lumpfish represent the dominant species in terms of numbers produced (>90\%). The rest of the farmed cleaner fish are ballan wrasse. Vaccination of farmed ballan wrasse against selective bacterial fish pathogens has been initiated. Lumpfish farming activity in Norway has increased radically in recent years, with more than 30 active producers in 2016, and 13.4 million lumpfish reported to have been sold in 2015. While official numbers for 2016 are not yet available, the industry reports 17.5 million produced, and ambitiously forecast production of more than 30 million fish in 2017. The increased popularity of lumpfish compared with wrasse seems, essentially, to derive from a perception that lumpfish are more robust to transport/handling etc., retain their lice eating activity at lower water temperature, and have a considerably shorter production time. Lumpfish broodstocks are wild-caught, although efforts are being directed towards the achievement of consecutive farmed generations. Vaccination programs for farmed lumpfish have been implemented [3].

\section{Sustainable management of cleaner fish in salmonid farm}

In the natural environment, wrasse is considered as facultative cleaner species. They are generalist forager and they do not adopt more dedicated cleaning roles within the reef community [5]. They are different from an obligate cleaner in which all of their nutrition derives from their client during such symbiotic interaction, without which they would perish [4]. Wrasse and lumpfish are facultative cleaner fish which means they are not entirely dependent on cleaning behavior for their nourishment. Part of sustainable management in cages and pens is the provision of supplementary feeding for cleaner fish. It has been shown in experimental trials that wrasses held in clean net pens - without other food than the sea lice - lose weight due to starvation [2]. In fact, supplementary feed for cleaner wrasse when sea lice numbers were low and especially in the first year and after stocking is required. In most cases, the farms provided a supplementary feed of crushed shore crab or mussels when wrasse was initially stocked. The feed was presented in a number of ways, for example in bags made from netting, open baskets, and in hides used for wrasse capture. The use of this feed also encouraged wrasse not to seek feed in the mortality collection sock at the bottom of the salmon net. The only negative view presented about the practice was that, wrasse acclimated to feeding on supplementary feed took some time to feed on sea lice again [30]. Failure to do so led to recent data suggesting that about one-third of lumpfish may die of starvation in salmon cages within a few weeks after deployment. Understanding their feeding preferences is, hence, essential. Increasing delousing efficiency without compromising welfare or growth is a major research priority. Lumpfish are opportunistic, omnivorous feeders and will not only feed on sea-lice, but also on salmon pellets and many organisms found in sea cages, which need to be kept clean to encourage delousing behavior [19]. It was observed that wrasse 
maintain their body condition on marine biofouling present in the nets as reflected in their gut content. These biofouling organisms reduce the incentive for wrasse to eat sea lice. For this reason, the farm should have inspected the net and ensured that biofouling was not too advanced [30]. Limiting alternative food sources for the corkwing and goldsinny wrasse encourages them to clean thus maintaining clean nets improved the cleaning behavior of wrasse in a cage [17]. It might be possible to increase delousing efficiency by selecting individuals that have a greater affinity for consuming sea-lice, and perhaps also by conditioning them prior to deployment [19]. Recent finding suggests that pre-deployment acclimatisation of farmed ballan wrasse to sea-cage conditions positively improved delousing performance [31].

The coexistence of two species of cleaner fish is considered promising due to its efficacy in removing sea lice because of its different cleaning behavior. One of the tandem cleaner fish used to control sea lice on two Irish salmon farms was the combination of corkwing and goldsinny wrasse, which successfully controlled sea lice infestations on Atlantic smolts in the west Irish coast. Corkwing cleaning activity was observed throughout the day and peaked early in the morning while goldsinny peaked in the middle of the day [17]. Another advantage of using two different species of cleaner fish in a salmon farm is the limited adaptation to low temperature. The study conducted by Treasurer [30] demonstrates that the stocking of wrasse on five salmon farms significantly reduced the numbers of mobile lice. However, sea lice numbers increased overwinter. Wrasse tends to eat more sea lice than lumpfish but is not suitable below $6^{\circ} \mathrm{C}$. Lumpfish, on the other hand, can continue to feed at $4^{\circ} \mathrm{C}$ and have the potential to survive the winter even in the northernmost salmon farm, due to its broad geographical distribution. Thus, a two-species cleaner fish system involving wrasse and lumpfish might be an advantage. Through this practice, the weakness of the other cleaner fish might be the strength of another, thus sustainable cleaning behavior activity of cleaner fish will be established in the pen or cage.

In nature cleaner wrasses usually have a well-established cleaning station. In this cleaning station where wrasses seek refuge and rest. Since a cage and pen is an artificial environment, the provision of shelter in the cage is considered sustainable management for cleaner fish. There are a number of reasons enumerated by Treasurer [30] why the installment of hides or refuge is very important to the welfare of wrasse. It serves protection from temperature and environmental conditions as well as bad weather. Hides are essential when wrasse are less active at low temperatures. It provides an area for resting from salmon and also protection from tidal flows. It gives an area to sleep in and provides protection. Wrasse are known to be inactive and unresponsive in darkness (asleep) and may give uneasy access to predators. And it was also found that these hides did buffer fluctuations in salinity and temperature and improved wrasse survival. The depth of the hides is also important and these should be located mid-depth in the pen or where salmon spend much of their time, to enable wrasse to readily swim and mix with the salmon. The use of hides to reduce stress in wrasse and to increase survival, especially overwinter has been beneficial. As reported in corkwing wrasse, there was no cleaning activity of wrasse at dusk and many of the wrasse found to be resting and sometimes competing for resting spaces such as the shelters provided. The importance of artificial shelter was also evident in goldsinny when the day length became shorter and temperature reduced, the goldsinny appeared less active, and swimming activity was reduced and fish tended to concentrate near the artificial shelters [17]. The net pens with salmonid fish represent an environment that is very different from the shallow water zone inhabited by these cleaner fish species naturally. In the wild, wrasses will always stay near the bottom, close to the available shelter, and lumpfish juveniles often attach to seaweed and hide in the vegetation. Lack of shelter and areas to rest will presumably result in an increased stress level and reduced welfare for these fish. Most fish farmers try to improve the conditions for the cleaner fish, e.g., by offering shelters made of rows of artificial (plastic) seaweed or different kinds of artificial shelter like stacked tubes or boxes with "windows". Larger lumpfish should have access to firm surfaces for attachment. Areas with artificial shelter in the net pens may function as cleaning stations for the salmon. Without hides, small wrasses held together with large salmon or rainbow trout may be eaten by the salmonids. Predation is most common during the periods when the salmon or trout are starved prior to slaughter. Sufficient access to artificial cleaner fish refuges could possibly reduce this problem [3].

\section{Re-use of cleaner fish post-deployment increased sustainability}

Re-use of lumpfish post-deployment is another important area where sustainability can be increased, as the current practice of culling lumpfish after just one salmon production cycle has been criticized as being wasteful and has welfare implications. Opportunities for re-use may include the use of lumpfish post-deployment as broodstock for the selection of elite lines in captive breeding programs, as well as the harvesting of lumpfish for use in animal feeds and perhaps also for human consumption (including roe production). New markets for lumpfish have opened since Iceland banned discards in 2011 (only the roe was formerly collected), and in recent years, the species has become a newly discovered 
delicacy for Asian food markets. Increasingly, large numbers of frozen whole and filleted lumpfish are now being exported to China, bringing more than $€ 18$ Million year-1 $^{-1}$ to the Iceland economy. Prices paid for frozen lumpfish have escalated and currently sell on the internet at over $\$ 2$ per $\mathrm{kg}$. The re-use of lumpfish which have been feeding on sea lice, hence, constitute an attractive form of nutrient recycling, and might even represent a business opportunity [19]. Finally, biliverdin, a compound responsible for the blue coloration of ballan wrasse and lumpfish has several potential applications in research, medicine, and biotechnology, including fluorescence microscopy and as a storage medium for transplant organs. While large quantities could potentially be extracted from cultured ballan wrasse blood, the cost of extraction compared with other sources must be further studied [32].

\section{Conclusion}

Cleaner fish is a key species in species biodiversity, abundance, recruitment and distribution in a natural habitat. They play a very important role in the survival, growth and welfare of other fishes. Their presence made a certain location into a very rich fishing ground visited by different species of demersal, pelagic including cartilaginous fishes. The removal of cleaner fish from the natural environment may affect the overall health of the ecosystem. Because of higher demand in salmonid aquaculture, their over-exploitation from the natural habitat is possible. However, aquaculture may cope up with the demand of the expanding global industry of salmon through patching loopholes that the natural stock can no longer provide and sustain. Practices in cleaner fish aquaculture should be counter check to avoid discontinuity of the production. These include translocation and importation of cleaner fish from different regions. This activity will not only alter the genetic biodiversity of local cleaner fish, but it is also a possible introduction of pathogens. In such cases, development of aquaculture technology for local cleaner fish is being promoted. However, if there is no available cleaner fish in the area. Good aquaculture practices such as screening and quarantine of the newly arrived cleaner fish must be done. There are several management practices of cleaner fish after they are introduced into the cage or pen. Among these are the conditioning, screening, provision of supplemental feeding and shelter, and re-use of cleaner fish after the production cycle. These are to ensure a healthy and effective delousing activity of cleaner fish. Although the fallow period is not discussed in this paper, several researchers concluded that farming should have implemented the fallow period in their production cycle as part of sustainable practices.

\section{Compliance with ethical standards}

\section{Acknowledgments}

This review paper was an output of F316 (Fish Behavior Ecology) class of first Semester, A.Y. 2018-2019 at the University of the Philippines Visayas. The author wishes to thanks the Graduate Research and Education Assistantship for Technology (GREAT) Program of the DOST-PCAARRD for the scholarship grant. Likewise to Dr. Harold M. Monteclaro and Dr. Gerald F. Quinitio for the approval of the review topic.

\section{Disclosure of conflict of interest}

The author declares no possible conflict of interest from anyone.

\section{References}

[1] Elghafghuf A, Vanderstichel R, Hammell L and Stryhn H. (2020). Estimating sea lice infestation pressure on salmon farms: Comparing different methods using multivariate state-space models. Epidemics, 31, 100394.

[2] Skiftesvik AB, Bjelland RM, Durif CMF, Johansen IS and Browman HI. (2013). Delousing of Atlantic salmon (Salmo salar) by cultured vs. wild ballan wrasse (Labrus bergylta). Aquaculture, 402, 113-118.

[3] Rimstad E, Basic D, Gulla S, Hjeltnes B and Mortensen S. (2017). Risk assessment of fish health associated with the use of cleaner fish in aquaculture. Opinion of the Panel on Animal Health and Welfare of the Norwegian Scientific Committee for Food and Environment, VKM report, 32.

[4] Vaughan DB, Grutter AS, Costello MJ and Hutson KS. (2016). Cleaner fishes and shrimp diversity and a reevaluation of cleaning symbioses. Fish Fish, 1-19. 
[5] Dunkley K, Cable J and Perkins SE. (2018). The selective behavior of juvenile blue-headed wrasse (Thalassoma bifasciatum) in the Caribbean. Behavioral Processes, 147, 5-12.

[6] Grutter GS, Murphy JM and Choat JH. (2003). Cleaner fish drives local fish diversity on coral reefs. Current Biology, $13,64-67$.

[7] Skiftesvik AB, Blom G, Agnalt A, Durif CMF, Brownman HI, Bjelland RM and Mortensen S. (2014). Wrasse (Labridae) as cleaner fish in salmonid aquaculture - The Hardangerfjord as a case study. Marine Biology Research, 10, 3, 289-300.

[8] Barrett LT, Overton K, Stien LH, Oppedal F and Dempster T. (2020). Effect of cleaner fish on sea lice in Norwegian salmon aquaculture: A national scale data analysis. International Journal for Parasitology, in Article Press.

[9] Limbaugh C. (1961). Cleaning symbiosis. Scientific American, 205, 42-49.

[10] Randall JE. (1958). A review of the labrid fish genus Labroides, with descriptions of two new species and notes on ecology. Pacific Science, 12, 327-347.

[11] Bshary R. (2003). The cleaner wrasse, Labroides dimidiatus, is a key organism for reef fish diversity at Ras Mohammed national Park, Egypt. Journal of Animal Ecology, 72, 169-176.

[12] Waldie PA, Blomberg, SP, Cheney KL, Goldizen AW and Grutter AS. (2011). Long-term effects of the cleaner fish Labroides dimidiatus on coral reef fish communities. PLoS One, 6, 1-7.

[13] Faust E, Halvorsen KT, Andersen P, Knutsen H and Andre C. (2018). Cleaner fish escape salmon farms and hybridize with local wrasse populations. Royal Society Open Science, 5, 1-12.

[14] Sundt R and Jørstad KE. (1993). Population genetic structure of wrasse used as cleaner fish in Atlantic salmon farming in Norway. ICES, 30, 11.

[15] Sundt R and Jørstad KE. (1998). Genetic population structure of goldsinny wrasse, Ctenolabrus rupestris (L.), in Norway: Implications for future management of parasite cleaners in the salmon farming industry. Fisheries Management and Ecology, 5, 291-302.

[16] Potts GW. (1973). Cleaning symbiosis among British fish with special reference to Crenilabrus melops (Labridae). Journal of Marine Biology Association, U.K., 53, 1-10.

[17] Deady S, Varian SJ and Fives JM. (1995). The use of cleaner-fish to control sea lice on two Irish salmon (Salmo salar) farms with particular reference to wrasse behaviour in salmon cages. Aquaculture, 131, 73-90.

[18] Bjordal A. (1991). Wrasse as cleaner fish of farmed salmon. Progress in Underwater Science, 16, 17-29.

[19] Powell A, Treasurer JW, Pooley CL, Keay AJ, Lloyd R, Imsland AK and de Leaniz CG. (2018). Use of lumpfish for sea-lice control in salmon farming: Challenges and opportunities. Reviews in Aquaculture, 10, 683-702.

[20] Leclercq E, Zerafa B and Brooker AJ. (2018). Application of passive-acoustic telemetry to explore the behaviour of ballan wrasse (Labrus bergylta) and lumpfish (Cyclopterus lumpus) in commercial Scottish salmon sea-pens. Aquaculture, 495, 1-12.

[21] Yuen JW, Dempster T, Oppedal F and Hvas M. (2019). Physiological performance of ballan wrasse (Labrus bergylta) at different temperatures and its implication for cleaner fish usage in salmon. Biological Control, 135, 117-123.

[22] Cavrois-Rogacki T, Davie A, Monroig 0 and Migaud H. (2019). Elevated temperature promotes growth and feed efficiency of farmed ballan wrasse juveniles (Labrus bergylta). Aquaculture, 511, 734237.

[23] Imsland AK, Reynolds P, Eliassen G, Hangstad TA, Foss A, Vikingstad E and Elvegård TA. (2014a). The use of lumpfish (Cyclopterus lumpus L.) to control sea lice (Lepeophtheirus salmonis Krøyer) infestations in intensively farmed Atlantic salmon (Salmo salar L.). Aquaculture, 424, 18-23.

[24] Imsland AK, Reynolds P and Eliassen G. (2014b). Assessment of growth and sea lice infection levels in Atlantic salmon stocked in small-scale cages with lumpfish. Aquaculture, 433, 137-42. 
[25] Eliasen K, Danielsen E and Johannesen Ása. (2018). The cleaning efficacy of lumpfish (Cyclopterus lumpus L.) in Faroese salmon (Salmo salar L.) farming pens in relation to lumpfish size and seasonality. Aquaculture, 488, 6, 15.

[26] Havas M and Oppedal F. (2019). Physiological responses of farmed Atlantic salmon and two cohabitant species of cleaner fish to progressive hypoxia. Aquaculture, 512, 734353.

[27] Nytrø AV, Vikingstad E and Foss A. (2014). The effect of temperature and fish size on growth of juvenile lumpfish (Cyclopterus lumpus L.). Aquaculture, 434, 296-302.

[28] Nytrø AV. (2013). The effect of temperature and fish size on growth of juvenile lumpfish (Cyclopterus lumpus L.). Master's Degree Thesis in Fisheries Science, University of Tromsø, 80.

[29] Vestvik N. (2013). Lumpsuckers on the rise! Campbeltown: Aqua Kompetanse, 7770 Flatanger.

[30] Treasurer JW. (2013). Use of wrasse in sea lice control. Report to the Scottish Aquaculture Research Forum (SARF), Sarf, 068, 33.

[31] Brooker AJ, Davie A, Leclercq E, Zerafa B and Migaud H. (2020). Pre-deployment acclimatisation of farmed ballan wrasse (Labrus bergylta) to sea-cage conditions promotes behavior analogous to wild conspecifics when used as cleaner fish in Atlantic salmon (Salmo salar) farms. Aquaculture, Article In Press.

[32] Brooker AJ, Papadopoulou A, Gutierrez C, Rey S, Davie A and Migaud H. (2018). Sustainable production and use of cleaner fish for the biological control of sea lice: Recent advances and current challenges. Veterinary Record, $1-11$.

\section{How to cite this article}

Jumah YU. (2020). Cleaner fish behavioral ecology: Its implications toward wild fishery and salmonid aquaculture sustainability. GSC Advanced Research and Reviews, 3(2), 20-30. 